\title{
Clinical Survey of Pseudoexfoliation Syndrome
}

\author{
Hani Mahmood Mansoor ${ }^{1} \&$ Hayder Adnan Fawzi ${ }^{2}$ \\ ${ }^{1}$ Department of Ophthalmology, Fayha General Hospital, Basrah, Iraq \\ ${ }^{2}$ Department of Clinical Pharmacy, Baghdad Medical City, Baghdad, Iraq \\ Correspondence: Hayder Adnan Fawzi Department of Clinical Pharmacy, Baghdad Medical city, Baghdad, Iraq. \\ Tel: 964-772-262-7943. E-mail: hayder.adnan2010@gmail.com
}

Received: January 30, 2019 Accepted: April 18, 2019 Online Published: April 24, 2019

doi:10.5539/gjhs.v11n5p144 URL: https://doi.org/10.5539/gjhs.v11n5p144

\begin{abstract}
Objective: Assess the prevalence of PEX and identify the associated glaucoma and cataract.

Study Design and Methodology: A sample of 6,650 patients (age $\geq 40$ years) that attended the single ophthalmic private clinic for different complaints, for five years (January 2013 until January 2018), those diagnosed with PEX enrolled in this study, with a total number of 296 patients.
\end{abstract}

Results: 14 (4.7\%) patients with age from 40-49 years, 54(18.2\%) from 50-59 years, 102 (34.5\%) from 60-69 years, and $126(42.6 \%)$ equal or older than 70 years. Close sex frequencies were observed, with $153(51.7 \%)$ males, and $143(48.3 \%)$ females. In the current study, the prevalence of PEX was $4.45 \%$ (95\% confidence interval (CI), 3.98-4.97). There was a statistically insignificant relationship between PEG or advanced glaucoma with age or sex, but cataract was significantly associated with older age and male sex.

Conclusion: The prevalence of Pseudoexfoliation syndrome was $4.45 \%$, with a sharp increase after the age of 50 years. Although the prevalence of PEG and advanced glaucoma increased with age, it was neither statistically associated with it, nor with sex. Cataract prevalence was associated with increased age and male sex.

Keywords: pseudoexfoliation, glaucoma, cataract, age, gender

\section{Introduction}

Pseudoexfoliation (PEX) syndrome is defined as an age-related disorder of the extracellular matrix with characteristic production with an accumulation of a fibrillary material progressively in different intraocular and extraocular tissues (Anastasopoulos, Founti, \& Topouzis, 2015). PEX is strongly associated with developing glaucoma (Ritch \& Schlotzer-Schrehardt, 2001). Pseudoexfoliative glaucoma (PEG) regarded as the commonest type of secondary open-angle glaucoma (Ritch, 2001), and usually with higher intraocular pressure, more clinically serious course and worse prognosis compared to primary open-angle glaucoma (POAG) (Heijl, Bengtsson, Hyman, \& Leske, 2009; Hyman, Heijl, Leske, Bengtsson, \& Yang, 2010; Leske et al., 2007).

Some population-based studies have shown a cross-sectional association of cataract with PEX, this could be due to alterations in the vasculature of iris and blood-aqueous barrier, and this affects the aqueous composition and subsequently could affect the lens metabolism, resulting in the formation of cataract (Kanthan, Mitchell, Burlutsky, Rochtchina, \& Wang, 2013). In the current study, the aim was to assess the prevalence of Pseudoexfoliation syndrome and to identify its associated complications; namely glaucoma and cataract.

\section{Method}

\subsection{Study Design and Setting}

The total sample of patients was 6,650 patients who attended a private ophthalmic center, for a period of 5 years, from January 2013 until January 2018, all undergone full ocular examination with slit-lamp biomicroscopy examination before and after full pupillary dilatation and then there were 296 patients diagnosed with ocular Pseudoexfoliation, which were enrolled in this study.

\subsection{Eye Examination}

Further ocular examination included; applanation tonometry, standard visual field perimetry, and optical coherence tomography for assessment of functional and structural changes. The presence of cataract, glaucoma (Pseudoexfoliation and advanced), history of diabetes, hypertension, or ischemic heart disease were all 
documented.

Advanced glaucoma defined as optic nerve near total cupping with/without severe loss of visual field within $10^{\circ}$ of point of fixation, indicating a scotoma encroaching on fixation or splitting it (Gessesse \& Damji, 2013).

\subsection{Ethical Clearance}

All of the participants provided their written consent to participate in this research after they were fully educated about the nature of the study. This study was approved by the scientific, ethical committee of the Fayha General Hospital. The study and all its procedure were done in accordance with the Helsinki Declaration of 1975, as revised in 2000.

\subsection{Statistical Analysis}

The data was handled and analyzed by $\operatorname{IBM}^{\odot} \operatorname{SPSS}^{\odot}$ (Statistical Package for the Social Sciences) Statistics Version 22. Chi-square (with $95 \%$ Confidence Interval) was the test used for categorical data, and $P$-values less than 0.05 were considered statistically significant throughout this study.

\section{Results}

In the current study, the prevalence of Pseudoexfoliation syndrome was $4.45 \%$ (95\% confidence interval (CI), 3.98-4.97). The most common age group was $\geq 70$ years which is slightly higher than $60-69$ years, similar distribution of gender observed, in this sample of patients DM, hypertension and IHD frequency was low as illustrated in Table 1.

Table 1. Demographic and clinical characteristic

\begin{tabular}{llll}
\hline Variables & & Number & \% \\
\hline & $40-49$ & 14 & 4.7 \\
Age groups & $50-59$ & 54 & 18.2 \\
& $60-69$ & 102 & 34.5 \\
\hline \multirow{2}{*}{ Sex } & $\geq 70$ & 126 & 42.6 \\
\hline Diabetes mellitus & Male & 153 & 51.7 \\
\hline Hypertension & Female & 143 & 48.3 \\
\hline Ischemic heart diseases & & 22 & 7.4 \\
\hline
\end{tabular}

There was no significant association between Pseudoexfoliative glaucoma (PEG) and advanced glaucoma with age, while cataract show statistically significant association with age in which advanced age group association with higher frequency of cataract, as illustrated in Table 2.

Table 2. Association between age groups with Pseudoexfoliative glaucoma, advanced glaucoma, and Cataract

\begin{tabular}{|c|c|c|c|c|c|}
\hline Age groups & $40-49$ & $50-59$ & $60-69$ & $\geq 70$ & p-value \\
\hline \multicolumn{6}{|c|}{ Pseudoexfoliative glaucoma, n (\%) } \\
\hline Present (110) & $5(35.7)$ & $18(33.3)$ & $42(41.2)$ & $45(35.7)$ & 0.761 \\
\hline Absent (186) & $9(64.3)$ & $36(66.7)$ & $60(58.8)$ & $81(64.3)$ & \\
\hline \multicolumn{6}{|c|}{ Advanced glaucoma, n (\%) } \\
\hline Present (84) & $4(28.6)$ & $12(22.2)$ & $34(33.3)$ & $34(27.0)$ & 0.501 \\
\hline Absent (212) & $10(71.4)$ & $42(77.8)$ & $68(66.7)$ & $92(73.0)$ & \\
\hline \multicolumn{6}{|l|}{ Cataract, n (\%) } \\
\hline Present (127) & $0(0.0)$ & $12(22.2)$ & $48(47.1)$ & $67(53.2)$ & $<0.001$ \\
\hline Absent (169) & $14(100.0)$ & $42(77.8)$ & $54(52.9)$ & $59(46.8)$ & \\
\hline
\end{tabular}


There was no significant association between Pseudoexfoliative glaucoma (PEG) and advanced glaucoma with gender, while cataract show statistically significant association with gender in which male show higher association with cataract, as illustrated in Table 3.

Table 3. Association between gender with Pseudoexfoliative glaucoma, advanced glaucoma, and Cataract

\begin{tabular}{|c|c|c|c|}
\hline Gender & Male & Female & p-value \\
\hline \multicolumn{4}{|c|}{ Pseudoexfoliative glaucoma, n (\%) } \\
\hline Present (110) & $60(54.5)$ & $50(45.5)$ & \multirow{2}{*}{0.450} \\
\hline Absent (186) & $93(50.0 \%)$ & $93(50.0)$ & \\
\hline \multicolumn{4}{|c|}{ Advanced glaucoma, n (\%) } \\
\hline Present (84) & $48(57.1)$ & $36(42.9)$ & \multirow{2}{*}{0.237} \\
\hline Absent (212) & $105(49.5)$ & $107(50.5)$ & \\
\hline \multicolumn{4}{|l|}{ Cataract, n (\%) } \\
\hline Present (127) & $120(94.5)$ & $33(19.5)$ & \multirow{2}{*}{$<0.001$} \\
\hline Absent (169) & $7(5.5)$ & $136(80.5)$ & \\
\hline
\end{tabular}

\section{Discussion}

In the current study the prevalence of Pseudoexfoliation syndrome was $4.45 \%$ (95\% confidence interval (CI), 3.98-4.97), this prevalence was comparable to results reported by Vijaya et al. (2015) (Vijaya et al., 2015) who examined 7774 subjects in south India, then followed them for six years, and found the prevalence of Pseudoexfoliation syndrome among that population to be $3.73 \%$ (95\% CI, 3.73-4.2), also in another study done by Jasna Pavičić-Astaloš, et al. (2016) in north-west Croatia (Pavičić-Astaloš et al., 2016), which included 5349 subjects and found the prevalence of Pseudoexfoliation syndrome among them to be $3.6 \%$, it's well known that the prevalence differs with age, sex, and more importantly with the geographic location of a population and ethnicity, also genetic predisposition like LOLX1 variants (Anastasopoulos, Founti \& Topouzis, 2015).

In the current study the prevalence of Pseudoexfoliation syndrome clearly increased with age, and this was compared to results of Jonas et al. (2013) (Jonas et al., 2013) in central India, who enrolled 4646 subjects and detected PES in 87 patients, and found that the prevalence was significantly related to age, although it's proven from the definition of the disease itself that it is age-related, but consistency of this proved that there was no shift of the disease to involve a lower age population.

In the current study, sex distribution of PEX was very similar with males forming $51.7 \%$ compared to $48.3 \%$ females, similar results were reported by Vijaya et al. (2015), with $44.7 \%$ male and $55.4 \%$ female, but Raşit Kilıç (2014) in Turkey (Kılıç et al., 2014) reported more male predominance with $66.04 \%$ male compared to $33.96 \%$ females, in their study which identified PEX in $212(10.1 \%)$ of the total 2103 participant, but another earlier Turkish study done by Cumurcu et al. (2010) (Cumurcu, Kilic, \& Yologlu, 2010) reported no sex difference in PEX prevalence.

The prevalence of diabetes mellitus, hypertension, and IHD was relatively low in the current study, and these findings supported the results of Thessaloniki Eye Study, done by Anastasopoulos, et al. (2011) (Anastasopoulos et al., 2011) who found no relationship between these diseases and PEX, but in a review done by Andrikopoulos, et al. (2014) (Andrikopoulos, Alexopoulos, \& Gartaganis, 2014) they mentioned that PEX could by a risk factor for developing cardiovascular disease or they are different manifestations of the same pathologic condition.

In the current study the prevalence of PEG was 110(37.2\%), and the prevalence of advanced glaucoma cases from them was $84(28.4 \%)$, and although showed statistically insignificant relationship with age and with sex, there was an increase in prevalence of PEG and advanced glaucoma with increasing age and slightly more in males, this result was comparable to results of Jasna Pavičić-Astaloš, et al. (Pavičić-Astaloš et al., 2016) who showed the prevalence of PEG to be $23.6 \%$ with no sex difference, also the result of Seng Lee (2015) in Singapore ( Lee, Wong, \& Ho, 2015) showed that the mean age for PEX patients with or without PEG had no statistically significant difference, and there were statistically significant more males having PEG than females, on the other hand, Jonas, et al., (Jonas et al., 2013) reported that after age adjustment for a multivariate analysis; PEX was not related to open-angle glaucoma. Another study was done by Tanushree and Gowda, (2014) in India, they examined 100 
patients diagnosed with PEX and screened them for glaucoma, 17.0\% of them had PEG, 10 (58.8\%) was male and $7(41.2 \%)$ were females, who also reported that, although the prevalence of PEX was higher in females, PEG was more in male. In contrast to this, a large cohort study in the USA done by Kang et al. (2012) (Kang, Loomis, Wiggs, Stein, \& Pasquale, 2012) showed that male was $68 \%$ less likely to develop PEG than women, this varying reports about sex and PEG indicates that there are still undiscovered confounder factors that bias the results of each study toward a certain sex.

The prevalence of cataract among patients with PEX in the current study was $42.9 \%$, which was comparable to the results of Yildirim, et al. (2017) (Yildirim, Yasar, Gursoy, \& Colak, 2017) in Turkey, who reported that 55.0\% of the 100 patients with PEX suffered cataract compared to $35.0 \%$ of the 1909 other subjects without PEX. The current study showed that there was a statistically significant association between older age groups and male sex with cataract. It known that cataract prevalence increases with age in patients with PEX or without it (Plateroti, Plateroti, Abdolrahimzadeh, \& Scuderi, 2015). In the current study males with cataract were the majority $120(94.5 \%)$ compared to females 7(5.5\%), a less than this male predominance was reported by Gelaw et al. (2012) in south-east Ethiopia (Gelaw \& Tibebu, 2012) with 68.7\% male compared to $31.3 \%$ of females suffering from cataract and Pseudoexfoliation, this higher male ratio might be explained as male are usually independent and can have access to medical care easier than female in such societies.

\section{Conclusion}

The prevalence of Pseudoexfoliation syndrome was 4.45\% (95\% confidence interval (CI), 3.98-4.97), with a sharp increase after the age of 50 years. Although the prevalence of PEG and advanced glaucoma increased with age, it was neither statistically associated with it, nor with sex. Cataract prevalence was associated with increased age and male sex.

\section{Acknowledgments}

We the authors extend their thanks for the medical staff in Fayha General Hospital in Basrah for their help in completing this work.

\section{Competing Interests Statement}

The authors declare that there are no competing or potential conflicts of interest.

\section{References}

Anastasopoulos, E., Founti, P., \& Topouzis, F. (2015). Update on pseudoexfoliation syndrome pathogenesis and associations with intraocular pressure, glaucoma and systemic diseases. Current Opinion in Ophthalmology, 26, 82-89. https://doi.org/10.1097/ICU.0000000000000132

Anastasopoulos, E., Topouzis, F., Wilson, M. R., Harris, A., Pappas, T., Yu, F., ... \& Coleman, A. L. (2011). Characteristics of pseudoexfoliation in the Thessaloniki Eye Study. J Glaucoma, 20, 160-6. https://doi.org/10.1097/IJG.0b013e3181d9d8bd

Andrikopoulos, G. K., Alexopoulos, D. K., \& Gartaganis, S. P. (2014). Pseudoexfoliation syndrome and cardiovascular diseases. World Journal of Cardiology, 6, 847-854. https://doi.org/10.4330/wjc.v6.i8.847

Cumurcu, T., Kilic, R., \& Yologlu, S. (2010). The frequency of pseudoexfoliation syndrome in the middle Black Sea region of Turkey. European Journal of Ophthalmology, 20, 1007-1011. https://doi.org/10.1177/112067211002000621

Gelaw, Y., \& Tibebu, Y. (2012). Clinical Characteristics of Cataract Patients with Pseudoexfoliation Syndrome at Jimma University Specialized Hospital, South West Ethiopia. Ethiopian Journal of Health Sciences, 22, 1-6

Gessesse, G. W., \& Damji, K. F. (2013). Advanced Glaucoma: Management Pearls. Middle East African Journal of Ophthalmology, 20, 131-141. https://doi.org/10.4103/0974-9233.110610

Heijl, A., Bengtsson, B., Hyman, L., \& Leske, M. C. (2009). Natural History of Open-Angle Glaucoma. Ophthalmology, 116, 2271-2276. https://doi.org/10.1016/j.ophtha.2009.06.042

Hyman, L., Heijl, A., Leske, M. C., Bengtsson, B., \& Yang, Z. (2010). Natural history of intraocular pressure in the early manifest glaucoma trial: A 6-year follow-up. Arch Ophthalmol, 128, 601-7. https://doi.org/10.1001/archophthalmol.2010.78

Jonas, J. B., Nangia, V., Matin, A., Bhojwani, K., Sinha, A., Khare, A., Agarwal, S., \& Bhate, K. (2013). Pseudoexfoliation: normative data and associations. The Central India Eye and Medical Study. PLoS One, 8, e76770. https://doi.org/10.1371/journal.pone.0076770 
Kang, J. H., Loomis, S., Wiggs, J. L., Stein, J. D., \& Pasquale, L. R. (2012). Demographic and geographic features of exfoliation glaucoma in 2 United States-based prospective cohorts. Ophthalmology, 119, $27-35$. https://doi.org/10.1016/j.ophtha.2011.06.018

Kanthan, G. L., Mitchell, P., Burlutsky, G., Rochtchina, E., \& Wang, J. J. (2013). Pseudoexfoliation syndrome and the long-term incidence of cataract and cataract surgery: the blue mountains eye study. Am J Ophthalmol, 155 , 83-88.e1. https://doi.org/10.1016/j.ajo.2012.07.002

Kılıç, R., Sezer, H., Çomçalı, S. Ü., Bayraktar, S., Göktolga, G., Çakmak, Y., Çetin, A. B., \& Cumurcu, T. (2014). The Frequency of Exfoliation Syndrome in the Central Anatolia Region of Turkey. Journal of Ophthalmology, 2014, 5. https://doi.org/10.1155/2014/139826

Leske, M. C., Heijl, A., Hyman, L., Bengtsson, B., Dong, L., \& Yang, Z. (2007). Predictors of Long-term Progression in the Early Manifest Glaucoma Trial. Ophthalmology, 114, 1965-1972. https://doi.org/10.1016/j.ophtha.2007.03.016

Pavičić-Astaloš, J., Koluder, A., Knežević, L., Geber, M. Z., Novak-Lauš, K., Csik, T., ... Milošević, M. (2016). Prevalence of pseudoexfoliation syndrome and pseudoexfoliation glaucoma in population of north-west croatia aged 40 and over. Acta Clin Croat, 55, 483-489. https://doi.org/10.20471/acc.2016.55.03.19

Plateroti, P., Plateroti, A. M., Abdolrahimzadeh, S., \& Scuderi, G. (2015). Pseudoexfoliation Syndrome and Pseudoexfoliation Glaucoma: A Review of the Literature with Updates on Surgical Management. Journal of Ophthalmology, 2015, 9. https://doi.org/10.1155/2015/370371

Ritch, R. (2001). Perspective on exfoliation syndrome. J Glaucoma, 10. https://doi.org/10.1097/00061198-200110001-00013

Ritch, R., \& Schlotzer-Schrehardt, U. (2001). Exfoliation syndrome. Surv Ophthalmol, 45, $265-315$. https://doi.org/10.1016/S0039-6257(00)00196-X

Seng Lee, J. K., Ying Wong, E. P., \& Ho, S. L. (2015). Pseudoexfoliation syndrome at a Singapore eye clinic. Clinical Ophthalmology (Auckland, N.Z.), 9, 1619-1624. https://doi.org/10.2147/OPTH.S87155

Vijaya, L., Asokan, R., Panday, M., Choudhari, N. S., Ve Ramesh, S., Velumuri, L., \& George, R. (2015). Six-Year Incidence and Baseline Risk Factors for Pseudoexfoliation in a South Indian Population: The Chennai Eye Disease Incidence Study. Ophthalmology, 122, 1158-1164. https://doi.org/10.1016/j.ophtha.2015.02.007

Yildirim, N., Yasar, E., Gursoy, H., \& Colak, E. (2017). Prevalence of pseudoexfoliation syndrome and its association with ocular and systemic diseases in Eskisehir, Turkey. International Journal of Ophthalmology, 10, 128-134. https://doi.org/10.18240/ijo.2017.01.21

\section{Copyrights}

Copyright for this article is retained by the author(s), with first publication rights granted to the journal.

This is an open-access article distributed under the terms and conditions of the Creative Commons Attribution license (http://creativecommons.org/licenses/by/4.0/). 